\title{
Shakedown of a Thick Cylinder With a Radial Crosshole
}

\author{
Duncan Camilleri", Donald Mackenzie and Robert Hamilton \\ Department of Mechanical Engineering \\ University of Strathclyde \\ 75, Montrose Street \\ Glasgow G1 1XJ \\ Scotland, U.K.
}

\begin{abstract}
The shakedown behaviour of a thin cylinder subject to constant pressure and cyclic thermal loading is described by the well known Bree diagram. In this paper, the shakedown and ratchetting behaviour of a thin cylinder, a thick cylinder and a thick cylinder with a radial crosshole is investigated by inelastic finite element analysis. Load interaction diagrams identifying regions of elastic shakedown, plastic shakedown and ratchetting are presented. The interaction diagrams for the plain cylinders are shown to be similar to the Bree Diagram. Incorporating a radial crossbore, $30 \mathrm{~mm}$ diameter or less, in the thick cylinder significantly reduces the plastic shakedown boundary on the interaction diagram but does not significantly affect the ratchet boundary. The radial crosshole, for the geometry considered in this study, can be regarded as a local structural discontinuity and neglected when determining the maximum shakedown or (primary plus secondary stress) load in Design by Analysis. This may not be apparent to the design engineer and no obvious guidance, for determining whether a crosshole is a local or global discontinuity, is given in the codes.
\end{abstract}

\section{Nomenclature}

$$
\begin{array}{cl}
R_{i} & \text { Inner radius of cylinder (m) } \\
R_{o} & \text { Outer radius of cylinder (m) } \\
R_{c} & \text { Crosshole radius (m) } \\
L & \text { Cylinder half length (m) } \\
v & \text { Poisson's ratio } \\
\sigma^{T} & \text { Thermal stress (MPa) } \\
\sigma^{p} & \text { Hoop stress (MPa) } \\
\sigma_{y} & \text { Yield stress (MPa) }
\end{array}
$$

\footnotetext{
${ }^{*}$ Email: d.camilleri@strath.ac.uk
} 
$\sigma_{y}^{m} \quad$ Modified yield stress (MPa)

E Young's Modulus (MPa)

$P_{L}^{B} \quad$ Limit load - Bree solution (MPa)

$P_{L}^{T} \quad$ Limit load - thick cylinder theory (MPa)

$\alpha \quad$ Coefficient of linear expansivity $\left({ }^{\circ} \mathrm{C}^{-1}\right)$

\section{Introduction}

Thick cylindrical pressure vessels used in high temperature and pressure process applications often incorporate openings in the shell for several reasons, including fluid transfer, instrumentation, bursting caps, etc. Incorporating these openings leads to stress concentration in the shell around the opening, which in practice will reduce the fatigue life of the vessel [1-3]. The limit pressure of the vessel is also reduced but to a much lesser degree, approximately in proportion to the loss of wall cross section [4]. The hole is also known to significantly reduce the elastic shakedown pressure of a vessel $[5,6]$. The elastic shakedown load is the highest cyclical load for which shakedown to an elastic response is demonstrated. When the elastic shakedown load is exceeded, the vessel may experience either plastic shakedown or ratchetting. The Design by Analysis (DBA) procedures given in the ASME Boiler \& Pressure Vessel Code Section VIII Div. 2 [7] permit plastic shakedown (or alternating plasticity) subject to appropriate (low cycle) fatigue considerations but ratchetting, which ultimately leads to incremental plastic collapse, is not permitted. In elastic DBA, the shakedown criterion is encapsulated in the $3 \mathrm{~S}_{\mathrm{m}}$ limit applied to primary plus secondary stress. This criterion is based on simple elastic shakedown concepts [8] and in practice requires the designer to identify and isolate any peak stress in the vessel before applying the criterion. Peak stress, is the constituent of elastic stress that arises due to local stress concentration effects at local structural discontinuities, such as small holes, fillets, welds, etc. Peak stress does not cause any noticeable distortion of the vessel or affect the global response. It does not lead to static or cyclic plastic collapse (but may give rise to fatigue cracking or brittle fracture).

Crossholes in thick cylinders are clearly structural discontinuities and these exhibit several characteristics of a local stress concentration. If the hole is regarded as a local structural discontinuity, two analysis models are required to assess the vessel. For global failure mechanisms, limit load and ratchetting, the local stress concentration feature should be neglected and the allowable loads calculated for a plain cylinder. For the local fatigue failure mechanism, a model representing the crosshole is required. This may be a Finite Element model of the actual configuration or, alternately, appropriate stress concentration factors should be applied to the plain cylinder model. However, the presence of crossholes does lead to a reduction of limit load approximately in proportion to the 
loss of cross section. This suggests that the crosshole may have some features of a global discontinuity. It may not, therefore, be appropriate to assume that the crosshole can be neglected when considering the other global failure mechanism of ratchetting. The validity of this assumption must be assessed by investigating the cyclic plasticity response of the vessel, in particular the effect the crosshole has on the boundary between alternating plasticity and ratchetting behaviour. The object of this paper is to determine the effect of the crosshole on the inelastic response by considering the shakedown and ratchetting behaviour of a plain thin cylinder, a plain thick cylinder and a thick cylinder with a radial crosshole subject to constant internal pressure and cyclic thermal loading .

\section{Modelling and analysis}

Three cylindrical shells with closed end conditions subject to constant internal pressure and a cyclic through wall thermal gradient were considered: a thin cylinder, a thick cylinder and a thick cylinder with crosshole. The dimensions are defined in Figure 1 and Table 1.

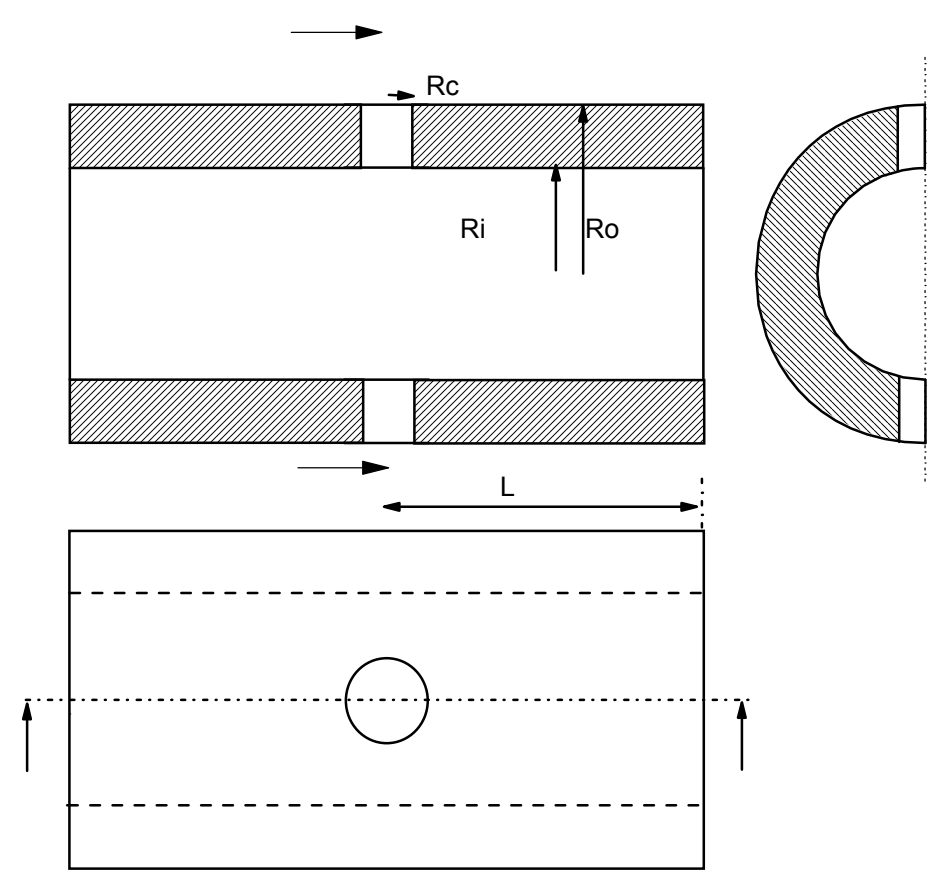

Figure 1. Geometry parameters.

Inelastic Finite Element Analysis was performed using the ANSYS program [9]. The plain thin and thick cylinders were modelled using 15 ANSYS plane 42 axisymmetric elements through thickness. In the thick crosshole cylinder, Solid 45 elements were used to model a quarter of the cylinder as shown in Figure 2. Symmetric boundary conditions were applied in the associated hoop and axial directions. The cylinders are subject to internal pressure in the main cylinder bore and in the crosshole bore. The main cylinder is 
assumed to have closed ends, represented by an applied plane sections remain plane condition and equivalent axial thrust. In accordance with the assumptions of the Bree analysis, the crosshole is assumed to be open and no radial thrust is applied to the open end.

\begin{tabular}{|l|l|l|l|l|}
\hline Model & $\operatorname{Ri}(\mathrm{m})$ & $\operatorname{Ro}(\mathrm{m})$ & $\operatorname{Rc}(\mathrm{m})$ & $\mathrm{L}(\mathrm{m})$ \\
\hline Thin & 0.365 & 0.385 & ---- & 0.450 \\
\hline Thick & 0.300 & 0.450 & ---- & 0.450 \\
\hline Crosshole & 0.300 & 0.450 & 0.030 & 0.450 \\
\hline
\end{tabular}

Table 1. Model Dimensions.

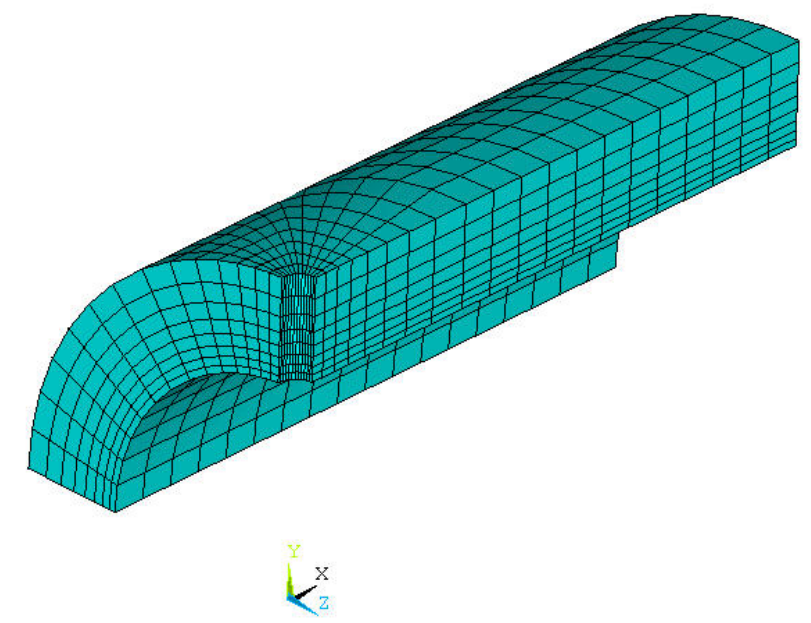

Figure 2. Finite Element Model of thick cylinder with crosshole

In all the models a constant internal pressure was applied to the cylinders first, followed by a thermal loading that was cycled over 25 cycles. The thermal gradient was applied to the cylinder as a linear through thickness gradient. The outside surface of the cylinder assumed ambient temperature while the internal surface fluctuated between ambient and higher temperatures.

The inelastic material model used was the standard Bilinear Kinematic Hardening material model with a plastic modulus of zero. In ANSYS if the plastic modulus is set to zero, the bilinear kinematic hardening material model becomes an elastic perfectly plastic non hardening plasticity model with an associative flow rule. A more advanced plasticity model, such as that suggested by Hassan [10] is 
not generally available to the designers and was not used in this study. The elastic, plastic shakedown and ratchetting boundaries where identified by investigating the accumulation of plastic straining over typically fifty cycles. Plastic shakedown is identified if the general trend is an alternating plastic straining while an accumulation in plastic straining leads to ratchetting. The results were benchmarked with the standard Bree solution to assess the accuracy of this method (refer to thin cylinder results below). The elasticplastic analysis procedures are based on the von Mises yield criterion but the ASME Code is based on the Tresca yield criterion, through the definition of Stress Intensity. The von Mises calculations can be modified for Code compliance in a simple but conservative manner by factoring the value of yield stress used in the analysis by $\sqrt{3} / 2$. This ensures the factored von Mises yield locus lies within the Tresca yield locus.

The material properties used in the investigation were representative of a high strength alloy steel (SA-723): Young's modulus $=184 \mathrm{GPa}$, design stress $\mathrm{S}_{\mathrm{m}}=310 \mathrm{MPa}$, Poisson's ratio $v=0.3$ and an expansivity of $13.35 \times 10^{-6}{ }^{\circ} \mathrm{C}^{-1}$. To conform with the assumptions of the Bree analysis, the temperature dependence of the material properties was not considered. The B\&PV Code specifies the value of yield to be used in limit analysis is $1.5 \mathrm{~S}_{\mathrm{m}}$, or $\sigma_{y}=465 \mathrm{MPa}$. Applying the $\sqrt{3} / 2$ Tresca factor therefore gives a modifies FEA yield stress $\sigma_{y}^{m}=402.7 \mathrm{MPa}$.

\section{Results}

The well known Bree [11] solution for shakedown and ratchetting of a thin-walled cylindrical shell (constant hoop, axial and linear thermal stresses, no radial stress) subjected to constant internal pressure and a cyclic temperature is represented graphically in the stress interaction diagram shown in Figure 3.

In the Bree diagram, $\sigma^{\mathrm{T}}$ is the maximum (cyclic) through thickness thermal stress, $\sigma^{\mathrm{P}}$ is the mean membrane hoop stress in the cylinder and $\sigma_{\mathrm{Y}}$ is the material yield stress. The analysis model in [11] is based on thin cylinder theory, open cylinder ends (i.e. zero axial stress) and a maximum stress yield criterion. Four distinct regions are identified in the diagram: elastic shakedown S, plastic shakedown (alternating plasticity) $\mathrm{P}$ and ratchetting regions R1 and R2, (associated with hoop only and axial/hoop ratchet 
respectively). The Code DBA procedures intend that the allowable design load history should be limited to the S and $\mathrm{P}$ regions only, (subject to appropriate safety factors).

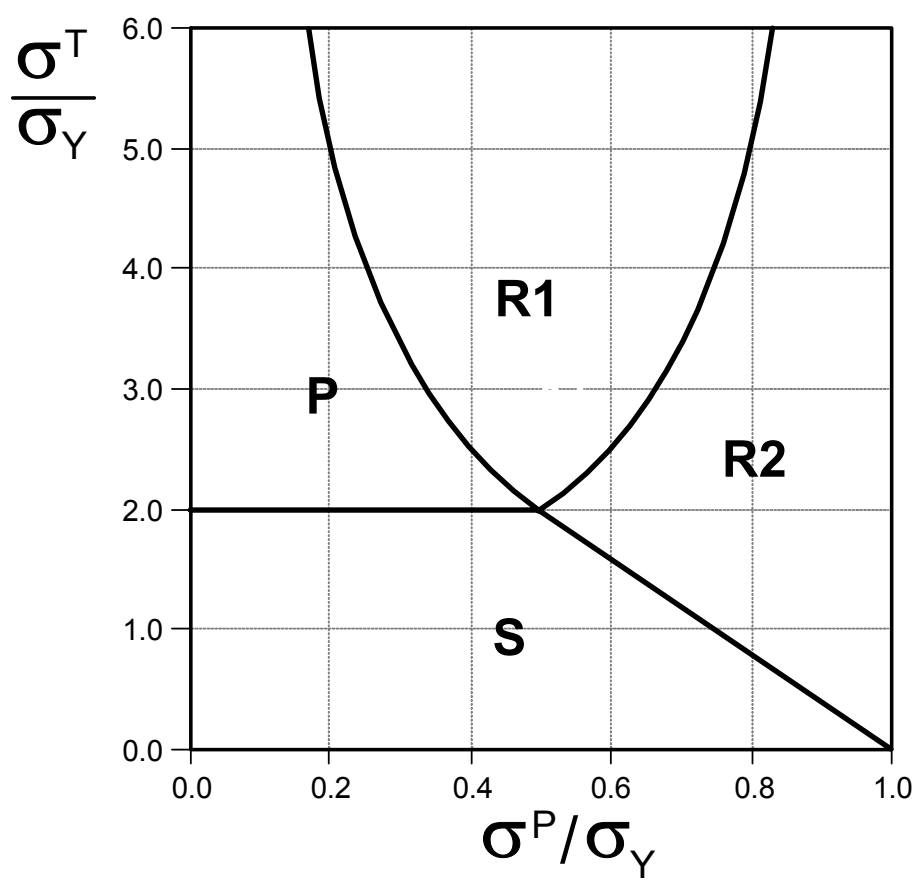

Figure 3. Bree diagram subject to hoop, axial and thermal stresses
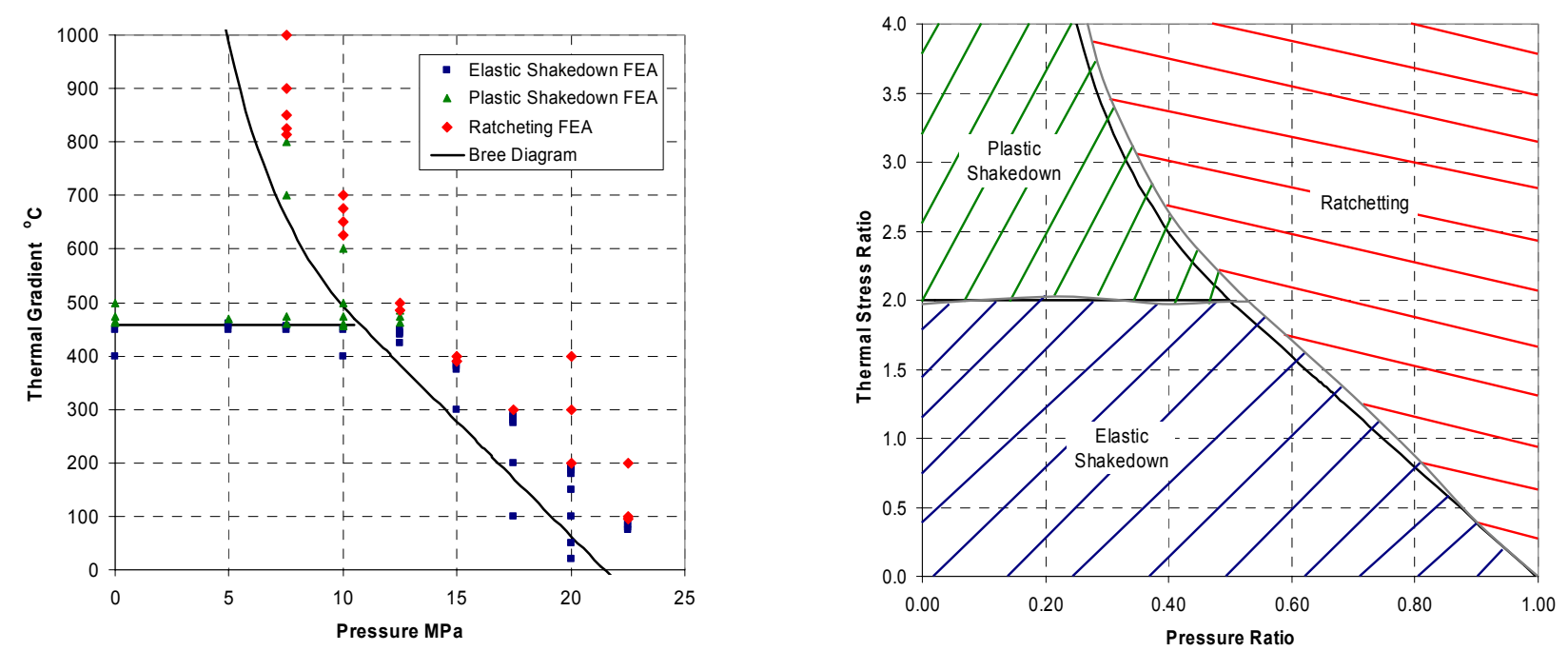

Figure 4. Thin cylinder (a) FEA data (b) interaction diagram; pressure ratio $\mathbf{P} / \mathbf{P}_{\mathrm{L}}$, thermal stress $\operatorname{ratio} \sigma_{\mathrm{T}} / \sigma_{\mathrm{y}}$

In the FEA investigation, the cyclic response of the thin cylinder was calculated for 83 combinations of constant pressure and cyclic thermal gradient and boundaries between different elastic-plastic responses identified using a bracketing methodology. The results of 
the individual analyses are represented by data points in Figure 4a. The Bree shakedown and ratchetting boundaries are also shown on Figure $4 \mathrm{a}$, assuming the same value of yield stress used in the FEA, $\sigma_{y}^{m}=402.7 \mathrm{MPa}$. Clearly, the results differ considerably for pressure dominated loading when presented in this format. This is due to the different assumptions and yield criteria in the two types of analyses. The Bree assumptions of thin cylinder theory and maximum stress criterion gives conservative values of elastic boundary/limit load in comparison with the modified von Mises solution. The limit pressure implicit in the Bree analysis is $P_{L}^{B}=\frac{\sigma_{y}^{m} t}{r}=\frac{402.7 \times 20}{375}=21.5 \mathrm{MPa}$ whereas thick cylinder theory and the Tresca criterion gives the well known limit load solution $P_{L}^{T}=\sigma_{y} \ln \left(\frac{R o}{R i}\right)=465 \ln \left(\frac{385}{365}\right)=24.8 M P a$ which is also the value obtained by FEA using the modified von Mises yield stress.

Figure $4 \mathrm{~b}$ presents the results of the FEA in an alternative different format. The applied pressure is normalised with respect to the thick cylinder/Tresca limit pressure $P_{L}^{T}$ in the x-axis and the maximum through thickness thermal stress $\sigma^{T}=\frac{E \alpha \Delta T}{2(1-v)}$ normalised with respect to yield stress $\sigma_{\mathrm{y}}{ }^{\mathrm{m}}=402.7$ in the y-axis MPa. The data presented in Figure 4a is used to identify regions of elastic shakedown (including a wholly elastic response), plastic shakedown and ratchetting. The Bree diagram, based on an un-modified material yield stress, $\sigma_{\mathrm{y}}=465$, is superimposed on the FEA results. In this instance, the thermal stresses and pressure obtained through Bree's solution, are normalized with respect to $\sigma_{\mathrm{y}}=465 \mathrm{MPa}$ and $P_{L}^{T m}=402.7 \ln \frac{385}{365}=21.5 \mathrm{MPa}$, respectively. In this format, the results of the FEA and Bree solutions are similar.

The shakedown and ratchetting boundaries for the thick cylinder were identified by performing 85 bracketing inelastic analyses. The results of the FEA are presented in Figure 5a, with the Bree diagram also shown. Shakedown and ratchetting regions identified by the FEA are shown in the normalised interaction diagram of Figure 5b, which also shows the Bree solution. Similar to thin cylinder solutions the FEA results are normalized with respect thick cylinder/Tresca limit pressure $P_{L}^{T}=465 \ln \frac{450}{300}=188.5 \mathrm{MPa}$ in the xaxis and the maximum through thickness thermal stress $\sigma^{T}=\frac{E \alpha \Delta T}{2(1-v)}$ normalised with respect to yield stress $\sigma_{\mathrm{y}}{ }^{\mathrm{m}}=402.7$ in the $\mathrm{y}$-axis $\mathrm{MPa}$. On the other hand the Bree solution is normalized with respect to $\sigma_{\mathrm{y}}=465 \mathrm{MPa}$ and $P_{L}^{T m}=402.7 \ln \frac{450}{300}=163.3 \mathrm{MPa}$, 
respectively. The FEA results and Bree solution are in general agreement, although the increase in thickness indicates a slight reduction in the magnitude of thermal stress at which plastic shakedown occurs. Furthermore the thick cylinder limit load yields higher a pressure when compared to the thin cylinder theory. This results in a shift of the Bree solution such that at zero thermal stress ratio the pressure ratio is 0.987 .
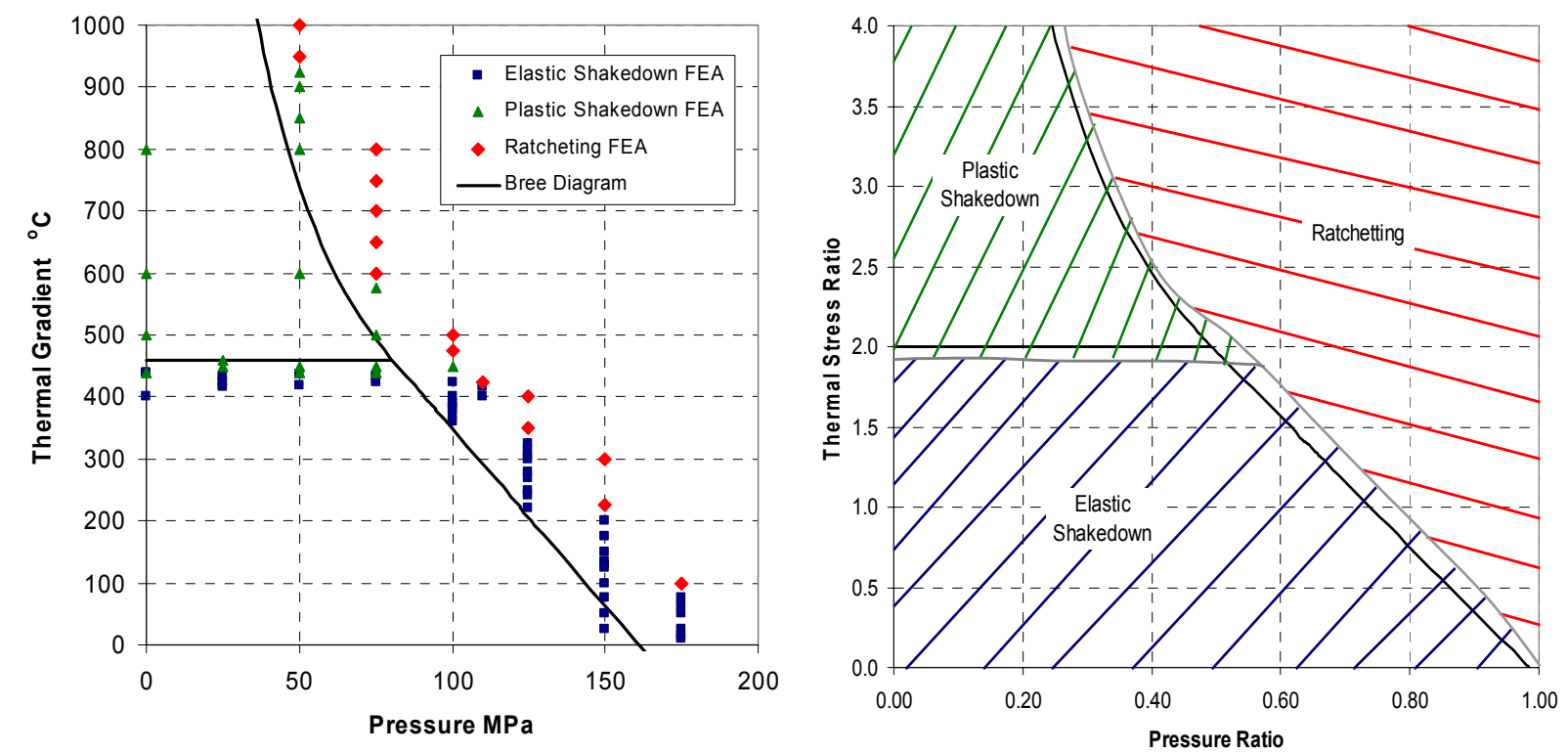

Figure 5. Thick cylinder (a) FEA data (b) interaction diagram; pressure ratio $\mathbf{P} / \mathbf{P}_{\mathrm{L}}$, thermal stress ratio $\sigma_{\mathrm{T}} / \sigma_{\mathrm{y}}$

The shakedown and ratchetting boundaries for the thick cylinder with radial crosshole were identified by performing 94 bracketing inelastic analyses. The results of the FEA are presented in Figure 6a and a normalised interaction diagram identifying the shakedown and ratchetting regions is shown in Figure 6b, with the Bree solution for a plain cylinder superimposed. The results show that the presence of the hole reduces the limit of the cylinder slightly but the effect on the boundary between elastic and plastic shakedown is more pronounced. The crosshole significantly reduces the thermal stress at which plastic shakedown occurs, as clearly seen in the interaction diagram of Figure 6b. However, the crosshole does not appear to significantly affect the boundary between shakedown and ratchetting behaviour for constant pressure and cyclic thermal loading.

\section{Conclusion}

The results of the cyclic inelastic analyses show that the presence of a crosshole $30 \mathrm{~mm}$ in diameter, greatly reduces the thermal load at which plastic shakedown occurs but does not significantly affect the ratchet boundary. This implies that a crosshole of the size studied 
and smaller, is essentially a local stress concentration, which will affect the fatigue life of the vessel but will not greatly influence the gross plastic deformation or incremental plastic collapse behaviour. The DBA of this component can therefore be achieved by reference to standard thick cylinder theory solutions for the global failure mechanisms (limit load and elastic shakedown load), augmented by Stress Concentration Factor data for peak stress and hence fatigue evaluation. This may not be apparent to the design engineer and no obvious guidance, for determining whether a crosshole is a local or global discontinuity, is given in the codes. Further investigation and parametric study is required for larger diameter crossholes where its presence will significantly influence the global failure mechanism of the structure, resulting in a reduction of the ratchetting load.
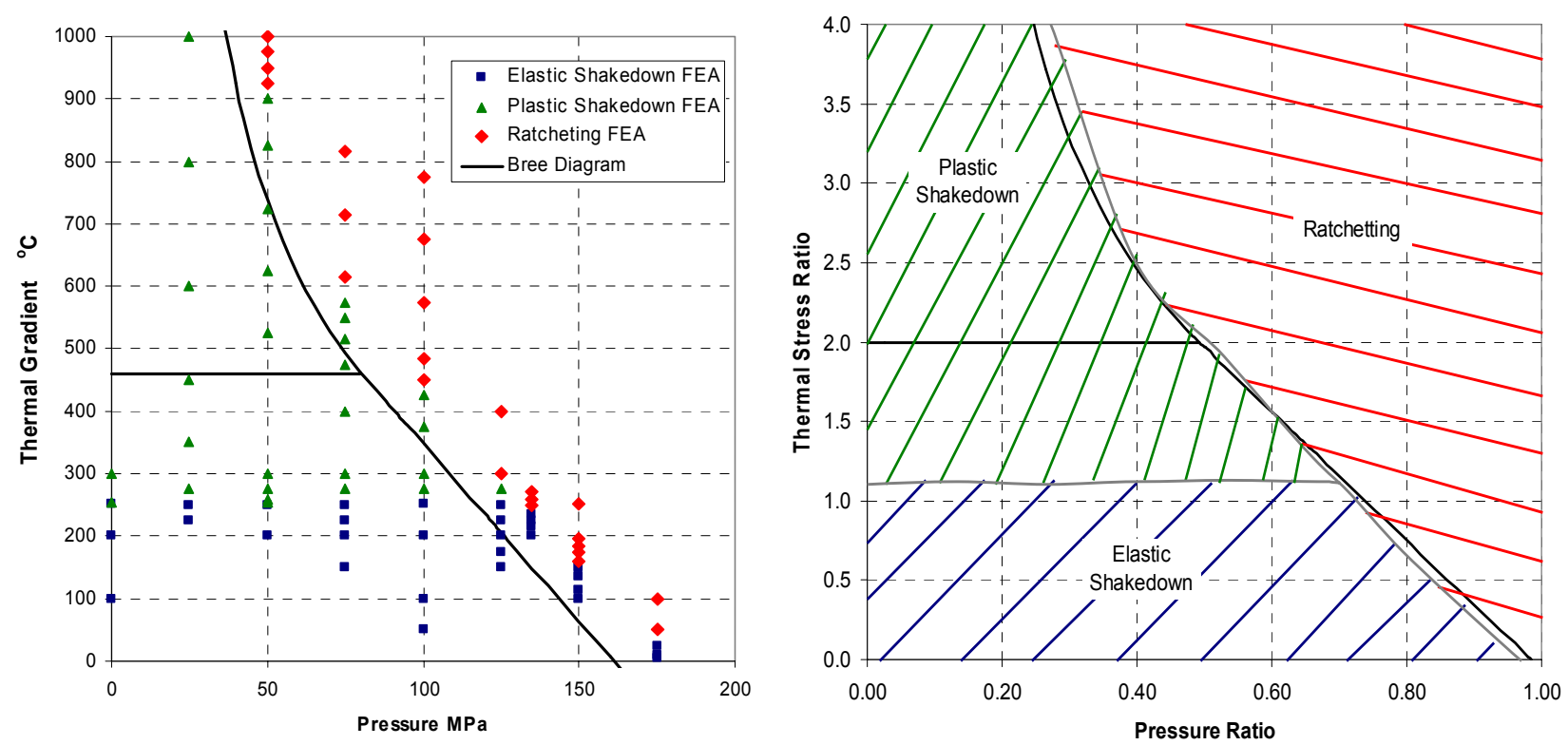

Figure 6. Thick cylinder with radial crosshole (a) FEA data (b) interaction diagram; pressure ratio $\mathrm{P} / \mathrm{P}_{\mathrm{L}}$, thermal stress ratio $\sigma_{\mathrm{T}} / \sigma_{\mathrm{y}}$

\section{Acknowledgements}

Special thanks goes to the Engineering and Physical Sciences Research Council who supported the project under research grant GR/S81841/01

\section{References}

1. Faupel, J. H. and Harris, D. B. "Stress concentration in heavy-walled cylindrical pressure vessels", Industrial Engineering and Chemistry, 1957, Vol. 49, No. 12, 1979-1986. 
2. Gerdeen J C. "Analysis of stress concentrations in thick cylinders with sideholes and crossholes", J. Eng. for Industry, Vol. 94, pp. 815-823, 1972.

3. Makulsawatudom P, Mackenzie D \& Hamilton R, "Stress Concentration at Crossholes in Thick Cylindrical Vessels," J. Strain Analysis for Engineering Design, Vol. 39, pp471-481, 2005.

4. Chaaban, A. and Baraké, N. "Elasto-plastic analysis of high pressure vessels with radial cross-bores", Proc. ASME PVP Conf., Vol. 263, pp. 67-71, 1993.

5. Makulsawatudom, P., Mackenzie, D. and Hamilton, R. "Shakedown of thick vessels with circular and elliptical radial crossholes". Pressure Equipment Technology: Theory and Practice, Professional Engineering Publishing Limited, Bury St Edmunds, pp. 6783, 2003.

6. Makulsawatudom P, Mackenzie D \& Hamilton R, "Shakedown Behaviour of Thick Cylindrical Vessels with Crossholes," Proc IMechE, Part E, Journal of Process Mech Eng, Vol. 218, pp133-141, 2004.

7. ASME, Boiler and Pressure Vessel Code, The American Society of Mechanical Engineers, New York, NY, 1998.

8. ASME, "Criteria of the ASME Boiler and Pressure Vessel Code for Design by Analysis in Sections III and VIII, Division 2," The American Society of Mechanical Engineers, New York, 1969. Reprinted in Pressure Vessel Design and Analysis - A Decade of Progress, The American Society of Mechanical Engineers, New York, 1972.

9. ANSYS version 9.0, 2005

10. Hassan T, Zhu Y \& Matzen V C, "Improved Ratcheting Analysis of Piping Components," Int. Journal of Pressure Vessels and Piping, Vol. 75, pp $643-652,1998$.

11. J. Bree, "Elastic-Plastic Behavior of Thin Tubes Subjected to Internal Pressure an Intermittent High-Heat Fluxes with Application to Fast-Nuclear-Reactor Fuel Elements", Journal of Strain Analysis, Vol. 2, No. 3, pp.226-238, 1967. 